\title{
THE GENETICS OF FLOWERING RESPONSE IN COTTON. III. FRUITING BEHAVIOR OF GOSSYPIUM HIRSUTUM RACE LATIFOLIUM IN A CROSS WITH A VARIETY OF CULTIVATED AMERICAN UPLAND COTTON ${ }^{1}$
}

\author{
B. M. WADDLE, 2 C. F. LEWIS, AND T. R. RICHMOND
}

Received November 7, 1960

\begin{abstract}
$A$ S a result of cotton collecting expeditions in southern Mexico and Central A America by J. O. Ware, T. R. Richmond, C. W. Manning, and S. G. STEPHENS during 1946-48, some 600 introductions were brought to the United States. In the past two years, STEPHeNs made additional collections in Central America and the West Indies; but only a few of these cottons have been studied in new plantings. Parts of the earlier collections have been grown at College Station, Texas; Santa Rita, Puerto Rico; Shambat, Sudan; Namulonge, Uganda; and Iguala, Mexico. On the basis of the African plantings and other studies, Hutchrnson (1951) described seven taxonomic races of Gossypium hirsutum L.

In the tropical locations, the $G$. hirsutum introductions flowered the first season they were grown; but many of them failed to initiate fruit forms before frost in the latitude of the Cotton Belt of the United States. Almost without exception, the stocks which flowered in the Cotton Belt belonged to the race which Hutchinson described as latifolium. This race was considered by Hutchrnson (1951) to be an annual form while the other six races-morrilli, richmondi, palmeri,
\end{abstract} punctatum, yucatanense, and marie-galante-were classified as perennials.

A. LANG (unpublished) found that types of cotton which failed to flower in the field at College Station, Texas, could be induced to flower by subjecting them to photoperiods of nine to ten hours; therefore, he considered them to be short-day plants. He was also able to induce flowering of the short-day types during long days by grafting them on a two-branched, day-neutral stock and then removing terminal buds, juvenile leaves, and fruit forms from the day-neutral portion after the branch had attained a length of 14 to 16 inches. At the same time, mature leaves were removed from the grafted branch.

A series of experiments was conducted to determine the inheritance of fruiting response in cotton. In the first paper Lewis and Richmond (1957) reported the results of studies involving marie-galante and a day-neutral variety. In the second paper Lewis and Richmond (1960) worked with crosses between short-

${ }^{1}$ Contribution from the Crops Research Division, Agricultural Research Service, U.S. Department of Agriculture, in cooperation with the Department of Agronomy, Texas Agricultural Experiment Station, College Station, Texas. Part of a dissertation submitted by senior author in partial fulfillment of the requirements for the Ph.D. degree. A part of this work was done under Project S-1 of the Hatch Act (Amended).

2 The senior author's present address: Plant Industry Station, Beltsville, Maryland.

Genetics 46: 427-437 April 1961. 
day and day-neutral $G$. barbodense L. stocks. The present paper combines the results of two separate experiments, both involving short-day forms of race latifolium in crosses with a day-neutral upland, also of race latifolium.

Since KLEBS (1918) recognized the influence of light on plants, voluminous literature has accumulated on the effects of duration and quality of light on many developmental functions of plants. Comprehensive review articles have been written by Whyte (1946), Murneek and Whyte et al. (1948), Wigglesworth et al. (1948), LeOpoLd (1951) and LANG (1952). The genetics of photoperiodism has not been investigated extensively, but enough reports are in the literature to show that the response of plants to length of day may have a monofactorial or a complicated multiple-factor genetic basis.

In an earlier paper of this series, Lewis and Richmond (1957) reported on the inheritance of flowering response in a cross between short-day G. hirsutum race marie-galante and a self-pollinated line of an old agricultural variety of $G$. hirsutum (Deltapine 14). Marie-galante remained vegetative when grown in the field during the long days of summer but set fruit when grown during short days of winter in the greenhouse. Deltapine 14 set fruit in about the same length of time in both environments. Under long-day conditions all $F_{1}$ plants initiated fruit forms, but only about half the plants developed one or more flowers. In each backcross the recurrent parent was dominant; i.e., all plants of the backcross to marie-galante failed to flower under field conditions and all plants of the backcross to Deltapine 14 flowered. The segregating $F_{2}$ population did not reveal a simple genetic ratio; neither was the segregation typical of quantitative inheritance. Under short-day conditions, all plants flowered; but even with a favorable photoperiod marie-galante carried a lateness factor not associated with response to length of day.

In the second experiment, Lewis and Richmond (1960) studied the inheritance of flowering response in a cross between Lengupa and Pima S-1, short-day and day-neutral stocks, respectively, of $G$. barbadense cotton. Under long-day conditions of summer, flowering was controlled by one gene pair and the shortday, nonflowering response was dominant to flowering. The monofactorial genetic basis of flowering response of this particular G. barbadense experiment was in sharp contrast to the complicated situation in the marie-galante experiment.

\section{MATERIALS AND METHODS}

The short-day parental material in these two studies was designated MW-84 (PI 163683) and MW-44. (PI 163643). Both of these stocks were collected by MANNING and Ware in Guatemala in 1948. The day-neutral parent in both experiments was an inbred line of Deltapine 14. According to Hutchinson (1951), all three stocks belong to race latifolium.

The basic plan of both experiments was essentially the same. The short-day parents were crossed with the day-neutral parent in the greenhouse during the winter, when both types would flower. Appropriate crosses and self-pollinations were made to produce $F_{2}$ and backcross seeds. The parental, $F_{1}, F_{2}$, and both 
backcross populations were grown in the field during the summer of 1951 under long-day conditions (13-14 hours of light) and a similar planting in the greenhouse during the winter under short-day conditions (9-10 hours of light). A graph of the hours of possible sunshine at College Station, Texas, was published by Lewis and Richmond (1957). In 1952, the field plantings of parental, $F_{1}, F_{2}$, and backcross populations were repeated and progeny tests made of selected segregants from the previous $F_{2}$ and backcross generations.

Field-grown plants were started in 6-ounce paper cups in the greenhouse and transplanted to the field at approximately two weeks of age, with 24-inch spacing within the rows and 40 inches between rows. A randomized block design with four replications was used in the field. In the greenhouse, potted plants were randomized on the benches and each progeny was replicated twice. The number of days from planting to the first visible fruit form (square), number of days to anthesis of first flower, and node number of first fruiting branch were recorded. In counting the nodes to the first fruiting branch, the cotyledonary nodes were recorded as nodes 1 and 2 .

The parental stocks also were grown in the greenhouse in a curtained area where the exposure to sunlight could be controlled. One planting was exposed to a $91 / 2$-hour photoperiod during the winter and another to a ten-hour photoperiod during the summer.

One season MW-84 was grown at College Station and Lubbock, Texas; Sacaton, Arizona; and Brawley and Shafter, California, to determine the influence of environment at these locations on flowering.

The recording of the first square, first flower, and node of first fruiting branch on two separate experiments in both field and greenhouse resulted in a large amount of data. The results of the experiments showed that the same interpretation of inheritance could be made from either the squaring or the flowering data and that crosses involving MW-84 behaved essentially the same as those with MW-44. In the interest of economy of space, these data were condensed and in some cases not presented in tabular form if they were not pertinent to the interpretation of the results.

\section{RESULTS}

The means of number of days from planting to first square and to anthesis of first flower for MW-84 and Deltapine 14 under winter and summer greenhouse conditions are given in Table 1 . Similar tests were conducted with MW-44, but they differ from the MW-84 data only in minor detail and are not presented in tabular form. The short-day cottons, MW-84 and MW-44, in the naturally short days of winter initiated fruit forms and developed flowers in about the same length of time as day-neutral Deltapine 14. In the longer days of summer, the short-day cottons failed to initiate fruit forms while Deltapine 14 flowered profusely under both long- and short-day conditions. By artificially shortening the photoperiod to ten hours, the short-day cottons were induced to square and to flower sporadically during the summer; however, the initiation and development 
TABLE 1

Mean number of days from planting to first square and to first flower of a short-day and day-neutral cotton in four greenhouse environments

\begin{tabular}{|c|c|c|c|c|}
\hline $\begin{array}{l}\text { Season and } \\
\text { day length }\end{array}$ & Population & $\begin{array}{l}\text { Number } \\
\text { of plants }\end{array}$ & $\begin{array}{l}\text { Mean no. } \\
\text { of days to } \\
\text { 1st square }\end{array}$ & $\begin{array}{l}\text { Mean no. } \\
\text { of days to } \\
1 \text { st flower }\end{array}$ \\
\hline Winter & MW-84 & 6 & 45.0 & 80.8 \\
\hline (91/2-hour day length) & D \& PL 14 & 6 & 45.0 & 82.5 \\
\hline Winter & MW-84 & 15 & 41.7 & 66.7 \\
\hline (Natural day length) & D \& PL 14 & 15 & 43.0 & 68.3 \\
\hline Summer & MW-84 & 10 & No square & No flower \\
\hline (Natural day length) & D \& PL 14 & 10 & 43.5 & 62.5 \\
\hline Summer & MW-84 & 10 & 91.0 & $105.0^{*}$ \\
\hline (10-hour day length) & D \& PL 14 & 10 & 50.5 & 76.0 \\
\hline
\end{tabular}

- Mean of four plants; six failed to flower.

of flowers were markedly delayed. During the summer even Deltapine 14 developed more slowly under the light-control curtain than on the greenhouse bench.

Experiments with other crops have shown that temperature may modify photoperiodic response. In the present experiments, the greenhouses could not be artificially cooled; but thermograph records of the actual temperature were kept. Mean maximum and minimum temperatures during the summer were higher, on the order of $10^{\circ}$ to $15^{\circ} \mathrm{F}$, than the comparable winter temperatures. This temperature difference could account for the delayed initiation and development of fruit forms even under a ten-hour photoperiod; but whatever the cause, Deltapine 14 was less sensitive than MW-84 and MW-44.

The short-day MW-84 was grown at College Station and Lubbock, Texas; Sacaton, Arizona; and Brawley and Shafter, California, in 1953. None of the MW84 plants produced flowers at College Station, but all flowered at Shafter, California. The day-length was slightly longer at Shafter, but temperature records showed that Shafter had cooler temperatures. Flowering at Lubbock, Sacaton, and Brawley was late and sporadic.

The summary of data on the squaring and flowering behavior of parental, $F_{1}$, $\mathrm{F}_{2}$, and backcross progenies involving short-day and day-neutral cottons is given in Table 2. Under the short-day conditions in the winter greenhouse all plants initiated fruit forms and developed flowers. Under these conditions MW-84 initiated and developed fruit slightly earlier than Deltapine 14; however, MW-44 was about seven days later. The mean number of days from planting to first square and first bloom in the $F_{1}, F_{2}$, and backcross to the short-day parent varied; but inspection of the data in Table 2 shows that there was never more than seven days difference in the means. Although this is significant statistically, the essential fact is that all plants in the short-day photoperiod of winter developed squares and flowers in approximately the same length of time. The backcross to Deltapine 14 in both cases was just as early as the parent, Deltapine 14, stock. 
Under long-day summer conditions in the field, the squaring and flowering behavior of parental, $F_{1}, F_{2}$, and backcross population were strikingly different. Contrary to expectations, some of the short-day parental plants occasionally squared and sporadically developed a flower. This small amount of fruiting activity occurred relatively late, and in vegetative appearance these plants were similar to the nonflowering types. The day-neutral Deltapine 14 initiated and developed flowers in about the same length of time in the field as in the greenhouse.

The $F_{i}$ plants in the field flowered only slightly later than the day-neutral parent indicating that flowering response was partially dominant to nonflowering.

The $F_{2}$ and backcross to the short-day parent segregated into squaring and nonsquaring and flowering and nonflowering classes. Since the segregations did not reveal a classic Mendelian ratio, the data on the various progenies are presented as percentage of plants that squared or flowered. Actually, the ratio of plants which flowered to those which did not, particularly in the MW-84 study, strongly suggests a monofactorial basis of inheritance; but squaring data and progeny tests in the next generation do not support this interpretation.

The fact that a higher percentage of plants squared than flowered indicates that many plants in these populations initiated fruit forms which aborted. Of course, drought, insects, and other environmental factors cause squares to shed;

TABLE 2

Summary of data on squaring and flowering behavior of cotton grown during long days of summer in the field in 1951 and during short days of winter in the greenhouse at College Station, Texas, 1951-52

\begin{tabular}{|c|c|c|c|c|c|c|c|c|}
\hline Progenies involving: & \multicolumn{2}{|c|}{$\begin{array}{l}\text { No. of plants } \\
\text { under observation } \\
\text { Field } \quad \text { G.H. }\end{array}$} & \multicolumn{2}{|c|}{$\begin{array}{l}\text { Percentage of } \\
\text { field* plants with } \\
\text { Squares Flowers }\end{array}$} & \multicolumn{2}{|c|}{$\begin{array}{l}\text { Days to } \\
\text { first squaret. } \\
\text { Field G.H. }\end{array}$} & \multicolumn{2}{|c|}{$\begin{array}{l}\text { Days to } \\
\text { first flowerit } \\
\text { Field } \quad \text { G.H. }\end{array}$} \\
\hline \multicolumn{9}{|l|}{ MW-84 and D \& PL 14} \\
\hline MW-84 & 45 & 5 & 4 & 0 & 84.5 & 49.0 & & 79.0 \\
\hline D \& PL 14 & 60 & 6 & 100 & 100 & $55.1 \pm .4$ & 53.3 & $76.3 \pm .6$ & 83.3 \\
\hline$F_{1}$ D \& PL $14 \times M W-84$ & 58 & 6 & 100 & 100 & $60.1 \pm .7$ & 52.5 & $86.5 \pm .4$ & 84.2 \\
\hline $\begin{array}{l}\mathrm{F}_{2} \mathrm{D} \& \mathrm{PL} 14 \times \mathrm{MW}-84 \\
\text { First backcross, }\end{array}$ & 571 & 29 & 94 & 88 & $62.7 \pm .5$ & 50.2 & $84.4 \pm .4$ & 81.7 \\
\hline $\begin{array}{l}\mathrm{F}_{1} \times \mathrm{MW}-84 \\
\text { First backcross, }\end{array}$ & 345 & 18 & 66 & 50 & $67.4 \pm .9$ & 50.6 & $90.3 \pm .9$ & 83.1 \\
\hline $\begin{array}{c}F_{1} \times \text { D \& PL 14 } \\
\text { MW-44 and D \& PL 14 }\end{array}$ & 354 & 17 & 100 & 100 & $56.3 \pm .6$ & 50.0 & $78.4 \pm .2$ & 81.8 \\
\hline MW-44 & 38 & 6 & 71 & 3 & $83.1 \pm .8$ & 57.7 & 97.0 & 88.0 \\
\hline D \& PL 14 & 43 & 6 & 100 & 100 & $56.6 \pm .4$ & 50.7 & $78.0 \pm .4$ & 83.1 \\
\hline$F_{1}$ D \& PL $14 \times M W-44$ & 45 & 6 & 100 & 100 & $57.6 \pm .5$ & 51.3 & $80.8 \pm .6$ & 81.1 \\
\hline $\begin{array}{l}\text { F. D \& PL } 14 \times \text { MW-44 } \\
\text { First backcross, }\end{array}$ & +419 & 30 & 99 & 90 & $60.7 \pm .4$ & 54.4 & $83.2 \pm .4$ & 85.3 \\
\hline $\begin{array}{l}\mathrm{F}_{1} \times \mathrm{MW}-44 \\
\text { First backcross, }\end{array}$ & 251 & 18 & 94 & 55 & $71.8 \pm .6$ & 54.4 & $93.0 \pm .6$ & 85.7 \\
\hline $\mathrm{F}_{1} \times \mathrm{D} \& \mathrm{PL} 14$ & 238 & 18 & 100 & 100 & $55.7 \pm .2$ & 48.8 & $78.0 \pm .2$ & 78.6 \\
\hline
\end{tabular}

- All greenhouse plants squared and flowered.

t Mean of those plants which squared and flowered. 
but in these experiments, irrigation and insect control reduced these causes of shedding to a minimum. Facultative shedding appeared to be the major cause of some plants failing to flower after having initiated squares.

The backcrosses to day-neutral Deltapine 14 flowered in essentially the same length of time as Deltapine 14.

The following season the parental, $\mathbf{F}_{1}, \mathbf{F}_{2}$, and backcross populations were grown again with smaller populations, and progeny tests were run on segregants from the $F_{2}$ and backcross populations from the preceding year. Segregants were selected from the frequency distribution of flowering in order to progeny-test early flowering and progressively later flowering plants. Plants which squared but failed to flower and plants which failed to initiate fruit forms were also chosen. Nonflowering and late-flowering plants were moved to the greenhouse where seeds for the progeny tests were produced.

The flowering data of the 1952 study involving MW-84 and Deltapine 14 are recorded in Table 3. Data on squaring were recorded in a similar way; but since

TABLE 3

Frequency distribution of number of days from date of planting to anthesis of first flower of $M W-84 \times D \& P L 14$ in the field, 1952, College Station, Texas

\begin{tabular}{|c|c|c|c|c|c|c|c|c|c|c|c|c|c|c|}
\hline \multirow[b]{2}{*}{ Progeny } & \multirow{2}{*}{$\begin{array}{c}\text { No. of } \\
\text { days to } \\
\text { first flower } \\
1951\end{array}$} & \multicolumn{10}{|c|}{ Flowering period in days } & \multirow{2}{*}{$\begin{array}{l}\text { Number of } \\
\text { plants that } \\
\text { flowered }\end{array}$} & \multirow{2}{*}{$\begin{array}{l}\text { Mean no. } \\
\text { of days } \\
\text { to first } \\
\text { flower }\end{array}$} & \multirow{2}{*}{$\begin{array}{l}\text { Number of } \\
\text { plants that } \\
\text { failed to } \\
\text { flower }\end{array}$} \\
\hline & & 70 & 75 & 80 & 85 & 90 & 95 & 100 & 105 & 110 & 115 & & & \\
\hline MW-84 & . & . & & . & 6 & 5 & 4 & 2 & 2 & . & & 19 & 92.1 & 30 \\
\hline $\begin{array}{l}\text { D \& PL } 14 \\
\text { F }\end{array}$ & . & . & 9 & 11 & . & & & . & . & & & 20 & 77.7 & . \\
\hline \multirow{2}{*}{$\begin{array}{l}F_{1} \\
F_{2}\end{array}$} & & & . & 15 & 5 & 1 & 2 & . & . & & & 23 & 82.8 & \\
\hline & . & 1 & 14 & 23 & 9 & 6 & 6 & 1 & 1 & & & 61 & 82.6 & 8 \\
\hline$F_{1} \times M W-84$ & 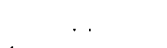 & . & & 2 & 9 & 2 & 3 & 1 & & & & 17 & 87.7 & 4 \\
\hline \multicolumn{2}{|l|}{$F_{1} \times D \&$ PL 14} & . & 22 & 20 & 1 & & & . & .. & & & 43 & 77.3 & $\cdots$ \\
\hline \multirow[t]{11}{*}{$\mathbf{F}_{3}$} & 75 & . & 20 & 31 & 16 & 4 & & . & . & & & 71 & 80.3 & . \\
\hline & 80 & . . & 16 & 36 & 4 & & & . & . & . & & 56 & 78.9 & \\
\hline & 85 & & 14 & 35 & 8 & 3 & 1 & & . & . & & 61 & 80.4 & 1 \\
\hline & 90 & . & 2 & 21 & 18 & 7 & 3 & & & & . & 51 & 83.9 & 2 \\
\hline & 95 & . & 8 & 23 & 13 & 8 & 3 & 3 & 1 & & & 59 & 83.8 & 5 \\
\hline & 100 & . & 18 & 15 & 4 & 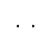 & 1 & . & . & . & . & 38 & 78.5 & \\
\hline & 105 & . & 1 & 10 & 4 & 3 & . & . & . & . & . & 18 & 82.7 & \\
\hline & 130 & . & 3 & 13 & 6 & 3 & . & . & . & . & & 25 & 81.7 & \\
\hline & 145 & . & & 3 & 8 & 4 & 2 & & 1 & 1 & & 19 & 89.1 & 1 \\
\hline & q. no flower & .. & 5 & 14 & 14 & 22 & 15 & 9 & 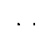 & $\ldots$ & . & 79 & 87.1 & 19 \\
\hline & No square & . & $\cdots$ & 17 & 21 & 16 & 8 & 2 & 3 & . & . & 67 & 88.7 & 28 \\
\hline \multirow{4}{*}{$\begin{array}{c}F_{2} \text { of }\left(F_{1} \times\right. \\
\text { MW-84) }\end{array}$} & 75 & . & 8 & 19 & 3 & 2 & . & . & . . & . & . & 32 & 79.3 & . \\
\hline & 80 & . & 2 & 6 & 6 & 4 & & . & . . & .. & . & 18 & 83.2 & \\
\hline & 85 & & 9 & 21 & 9 & 3 & 1 & . & . & . . & . & 43 & 80.9 & 3 \\
\hline & No square & . & 5 & 19 & 25 & 21 & 12 & 5 & 1 & 1 & . & 89 & 81.7 & 22 \\
\hline \multirow{4}{*}{$\begin{array}{l}F_{2} \text { of }\left(F_{1} \times\right. \\
\quad \text { D \& PL 14) }\end{array}$} & 75 & . & 1 & 59 & 54 & 9 & 1 & . & . & . & & 124 & 78.6 & . \\
\hline & 80 & . & . & 901 & 129 & 21 & 3 & & & . & & 214 & 78.0 & \\
\hline & 85 & .. & & 27 & 29 & 7 & 1 & & & . & & 64 & 78.4 & \\
\hline & 90 & . & & 8 & 9 & 6 & 1 & . & & $\ldots$ & & 24 & 79.6 & \\
\hline
\end{tabular}

* Mean of plants that flowered. 
the same interpretation of inheritance is gained from both flowering and squaring data, the squaring data are not presented in tabular form. The correlation coefficient between flowering $F_{2}$ plants and the mean flowering data of $F_{3}$ progenies was .56 for the progenies with MW-84 as short-day parent and .81 for $\mathrm{F}_{3}$ progenies involving MW-44. Both are highly significant. Of necessity nonflowering $F_{2}$ segregants could not enter into the calculations, and nonflowering segregants in the $F_{z}$ did not enter into the calculation of the mean. Thus the correlation coefficients were probably such that heritability of flowering response actually was higher than that estimated by the correlation coefficient.

The flowering data for the MW-44 study for both seasons are combined in Table 4. Examination of the data shows that more of the MW-44 parent plants flowered in 1952 than in 1951. The proportion of flowering to nonflowering plants was much higher in segregating populations in 1952. Eighteen flowering $F_{2}$ plants and seven nonflowering $\mathrm{F}_{2}$ plants were progeny-tested in $\mathrm{F}_{3}$. Although both the flowering and nonflowering $F_{2}$ plants segregated in $F_{3}$, the $F_{3}$ from the flowering $F_{2}$ plants produced a higher percentage of flowering segregants. These were an

TABLE 4

Segregation and mean number of days to flowering of various progenies of cotton grown under field (long-day conditions) at College Station, Texas

\begin{tabular}{|c|c|c|c|c|}
\hline \multirow[b]{2}{*}{ Progeny and year } & \multicolumn{2}{|c|}{ Number of plants } & \multirow{2}{*}{$\begin{array}{l}\text { Mean of plants } \\
\text { Meat did flower } \\
\text { that }\end{array}$} & \multirow[b]{2}{*}{ Remarks } \\
\hline & Flowering & Nonflowering & & \\
\hline \multicolumn{5}{|l|}{ MW-44: } \\
\hline 1951 & 1 & 37 & 97.00 & \\
\hline 1952 & 3 & 19 & $97.00 \pm 1.00$ & \\
\hline \multicolumn{5}{|l|}{ D \& PL 14: } \\
\hline 1951 & 43 & 0 & $78.05 \pm 0.40$ & \\
\hline 1952 & 24 & 0 & $77.33 \pm 0.38$ & \\
\hline \multicolumn{5}{|l|}{$F_{1}:$} \\
\hline 1951 & 45 & 0 & $80.76 \pm 0.60$ & \\
\hline 1952 & 26 & 0 & $79.27 \pm 0.37$ & \\
\hline \multicolumn{5}{|l|}{$\mathbf{F}_{2}:$} \\
\hline 1951 & 379 & 40 & $83.20 \pm 0.37$ & \\
\hline 1952 & 77 & 1 & $82: 05 \pm 0.76$ & \\
\hline \multicolumn{5}{|l|}{$F_{1} \times M W-44:$} \\
\hline 1951 & 139 & 112 & $92.96 \pm 0.59$ & \\
\hline 1952 & 40 & 8 & $90.03 \pm 0.84$ & \\
\hline \multicolumn{5}{|l|}{$F_{1} \times$ D \& PL 14: } \\
\hline 1951 & 238 & 0 & $78.00 \pm 0.21$ & \\
\hline 1952 & 46 & 0 & $78.00 \pm 0.48$ & \\
\hline$F_{3}: 1952$ & 396 & 20 & $81.54+$ & From flowering $F_{2}$ 's \\
\hline$F_{3}: 1952$ & 124 & 34 & 89.17 & From nonflowering $F_{2}$ 's \\
\hline $\mathrm{F}_{2}$ of $\left(\mathrm{F}_{1} \times \mathrm{MW}-44\right): 1952$ & 113 & 7 & 85.70 & From flowering $\mathrm{F}_{1} \times \mathrm{MW}-44$ \\
\hline$F_{2}$ of $\left(F_{1} \times M W-44\right): 1952$ & 58 & 49 & 89.45 & From nonflowering $\mathrm{F}_{1} \times \mathrm{MW}-44$ \\
\hline$F_{2}$ of $\left(F_{1} \times D \& P L 14\right): 1958$ & 52568 & 1 & 78.54 & \\
\hline
\end{tabular}

- Number of days from planting to first flower.

+ Correlation between flowering dates of $F_{2}$ plants and $F_{3}$ progenies $=0.81^{* *}$ 
average of eight days earlier than comparable $F_{3}$ segregants from nonflowering $F_{2}$ plants. With one exception, all plants from the $F_{2}$ of the backcross to Deltapine 14 flowered, and these progenies were essentially as early as Deltapine 14. The $\mathrm{F}_{2}$ of the backcross to MW-44 segregated into flowering and nonflowering types, and the mean flowering date of those plants which did flower was later than that of plants from the backcross to Deltapine 14. This is true of the means, but individual plants were recovered in the $F_{3}$ and the $F_{2}$ of the backcross to MW-44 which flowered as early as Deltapine 14. The mean flowering dates for all generations for the two years were remarkably close.

The node number of the first fruiting branch and productiveness of the plants in the MW-44 study were recorded from a field planting and from a winter greenhouse planting. The data are presented in Table 5. The node number data reveal about the same pattern of inheritance as square and flower data. Under short-day conditions in the greenhouse, all plants developed fruiting branches, and the mean position of the first fruiting branch was very nearly the same in the parents, $F_{1}, F_{2}$, and backcrosses. In the field, under long-day conditions, it was observed that late-squaring and flowering plants were those in which squares and flowers occurred at a higher node on the main stem. The data on production, expressed as the mean number of bolls per plant, emphasize how barren the short-day plants were under long-day conditions. The backcross to Deltapine 14 by this measure proved to be as fruitful as Deltapine and about three times as productive as the backcross to MW-44.

\section{TABLE 5}

Summary of data of node number of first fruiting branch for six progenies of cotton grown under long-day and short-day conditions

\begin{tabular}{|c|c|c|c|c|c|c|c|c|c|c|c|c|c|c|c|c|}
\hline \multirow[b]{2}{*}{ Progeny } & \multicolumn{12}{|c|}{ Node number of first fruiting branch } & \multirow{2}{*}{$\begin{array}{l}\text { Number } \\
\text { of } \\
\text { fruiting } \\
\text { branch }\end{array}$} & \multirow{2}{*}{$\begin{array}{c}\text { Total } \\
\text { plants }\end{array}$} & \multirow{2}{*}{$\begin{array}{c}\text { Mean node } \\
\text { of first } \\
\text { fruiting } \\
\text { branch }\end{array}$} & \multirow{2}{*}{$\begin{array}{c}\text { Mean } \\
\text { number } \\
\text { of bolls } \\
\text { per plant }\end{array}$} \\
\hline & 6 & 7 & 8 & 9 & 10 & 11 & 12 & 13 & 14 & 15 & 16 & 17 & & & & \\
\hline \multicolumn{17}{|c|}{1952 field planting (long-day conditions): } \\
\hline MW-44-5(\#2+15) & & & & & & & 1 & 2 & 2 & 4 & 2 & 3 & 25 & 39 & $14.9^{*}$ & 0.2 \\
\hline D \& PL 14 & & 5 & 14 & & & & & & & & & & 0 & 19 & 7.7 & 18.7 \\
\hline $\mathbf{F}_{1}$ & & & & 15 & 8 & 1 & & & & & & . & 0 & 24 & 9.4 & 15.4 \\
\hline $\mathbf{F}_{2}$ & 1 & 3 & 19 & 26 & 12 & 5 & 5 & 2 & 0 & 2 & 1 & . & 1 & 77 & $9.5^{*}$ & 14.6 \\
\hline $\mathrm{F}_{1} \times \mathrm{MW}-44$ & & & & 2 & 8 & 6 & 9 & 6 & 2 & 3 & 1 & 3 & 4 & 44 & $12.2^{*}$ & 5.7 \\
\hline $\mathrm{F}_{1} \times \mathrm{D} \times \mathrm{PL} 14$ & & 1 & 21 & 17 & 3 & 1 & & & & & $\cdots$ & & 0 & 43 & 8.5 & 18.9 \\
\hline \multicolumn{17}{|c|}{ 1952-53 greenhouse (short-day conditions): } \\
\hline MW-44-5(\#15) & & & & & 3 & 8 & 1 & & & & & & 0 & 12 & 10.8 & \\
\hline D \& PL 14 & . & & & 9 & 3 & & $\cdots$ & & & . & . & . & 0 & 12 & 9.3 & \\
\hline $\mathbf{F}_{1}$ & & & 1 & 5 & 5 & 1 & & & . & & . & & 0 & 12 & 9.5 & . . \\
\hline$F_{2}$ & $\cdots$ & & . & 2 & 2 & 7 & 1 & & 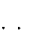 & & - & . & 0 & 12 & 10.6 & \\
\hline $\mathrm{F}_{1} \times \mathrm{MW}-44$ & & 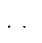 & . & . & 7 & 4 & 1 & . & . & . & . & . & 0 & 12 & 10.5 & $\ldots$ \\
\hline$F_{1} \times D \& P L 14$ & & & & 9 & 2 & 1 & & & & & & & 0 & 12 & 9.3 & $\ldots$ \\
\hline
\end{tabular}

- Mean value of those plants in the progeny which had a fruiting branch. 
DISCUSSION

The results of this study demonstrated that MW-84 and MW-44 plants squared and flowered sparingly or not at all during the long-day photoperiod of summer; but an environment was found in the naturally short days of winter in the greenhouse in which flowering occurred as soon as in the day-neutral parent. In the first paper of this series, Lewis and Rrchmond (1957) found the G. hirsutum race marie-galante was inherently later than Deltapine 14, regardless of the environment in which it was tested. With the short-day latifolium the difference in time of flowering in comparison with a day-neutral stock can be eliminated by subjecting the plants to 10 to 12 -hour photoperiods and moderate temperatures.

The lines of evidence obtained indicate that relatively cool temperatures may promote flowering of certain of the short-day cottons. (1) The plants exposed to ten hours of light during the summer in the greenhouse commonly were subjected to monthly mean maximum temperatures in excess of $100^{\circ} \mathrm{F}$. Although flowering occurred, it was delayed in comparison to similar plants grown in the winter greenhouse where mean maximum temperatures were around $85^{\circ}$. (2) Flowering was promoted in the 1952 season as compared to 1951, and weather records show that 1952 was the cooler season. (3) Flowering occurred at Shafter, California, in 1953, in comparison with total failure to flower at College Station, Texas; and Shafter had the longer day-length and a cooler growing season, particularly a lower minimum temperature.

The ratios of squaring and nonsquaring plants and flowering and nonflowering plants in the segregating generations do not justify a simple genetic model for the inheritance of flowering response. However, the higher parent-progeny correlations and behavior of the backcross populations indicate that the difference in flowering response of these short-day and day-neutral cottons has a genetic basis. Flowering of the two latifolium stocks was partially dominant. This is in contrast to the complete dominance of nonflowering of short-day G. barbadense reported by Lewis and Rrchmond (1960).

Hutchinson (1959) developed the thesis that Gossypium is essentially a genus of perennial shrubs native to the tropics and subtropics. In the tropics the perennial hirsutum stocks flower in the latter part of the rainy season and mature fruit in the dry season. According to Hutchinson, the onset of fruiting is governed by three major causes: (1) In young plants fruiting branches are not formed until a certain number of nodes develop on the main stem. This critical node number differs among cottons and is a genetic characteristic of the stock. (2) Photoperiod is a primary factor in the control of fruiting, and the stocks do not initiate flowers until the day-length is below 12 hours regardless of how many nodes the plant has developed. (3) Flowers may be initiated prior to the end of the rainy season, but the young flower buds shed if excessive water is available. When the rains abate and a favorable water balance is established, the fruit forms develop. When cottons were introduced into the southern United States, only a small portion of the types with a weak short-day requirement survived. 
In the past 150 years, selection pressure on the most adapted original introductions led to the development of the upland cottons which have the ability to set fruit on branches arising from low nodes on the main stem, are day-neutral in photoperiodic response, and continue fruit production in wet seasons.

Apparently, the fruiting response of the short-day latifolium stocks used in this study differs from that of cultivated day-neutral types largely by their reaction to photoperiod. Certain temperatures or other environmental effects may modify the response. This difference is conditioned by a complex multiple factor genetic mechanism. In marie-galante cottons, photoperiod is only one of the factors influencing flowering; seemingly the plants require a minimum number of nodes before flowering begins.

On the basis of one experiment by Lewis and Richmond (1960), the difference in flowering response of short-day and day-neutral G. barbadense is controlled by one gene pair and has had an independent evolution from hirsutum in this respect.

Certain practical considerations are evident from these studies. The nonflowering habit of introduced cottons can be eliminated in segregating generations when crosses are made with day-neutral stocks. Thus, the short-day response does not, per se, eliminate introduced cottons as sources of breeding material. In the past, sensitivity to the long summer days of the temperate zone acted as a barrier to the establishment of many stocks of cotton which thrive in the tropical zone. In the tropics, all the stocks of $G$. hirsutum classified as race latifolium appear to have similar gross characteristics. However, certain of them may carry genes for valuable economic characters in the temperate zone. Methods for exploiting the potential variability that has been locked in the short-day plants of race latifolium may now be devised.

These experiments were conducted in the field and in the greenhouse under constantly changing photoperiods and under the various total environments that existed during the course of the experiments. Climate-control chambers were lacking, and doubtless research with such equipment will be necessary to establish critical photoperiods and to determine the interaction of light and temperature.

\section{SUMMARY}

Fruiting response in cotton was studied in crosses involving short-day and dayneutral stocks from the same taxonomic race, $G$. hirsutum race latifolium. The data lead to the following general conclusions:

(1) Stocks belonging to the same taxonomic race may differ in response to length of day.

(2) Exposure of the short-day latifolium stocks used in this experiment to an inductive photoperiod induced them to flower as soon as day-neutral stocks.

(3) The short-day and day-neutral responses were primarily under genetic control; the day-neutral reaction was partially dominant. 
(4) The effects of short-day photoperiod can be modified by other factors, particularly temperature.

(5) Short-day cottons, which may contribute useful characteristics, can be utilized in applied breeding programs in the temperate zone.

\section{LITERATURE CITED}

Hutchinson, J. B., 1951 Intraspecific differentiation in Gossypium hirsutum. Heredity 5: 161-193.

1959 The Application of Genetics to Cotton Improvement. Cambridge University Press. Cambridge.

KLEBS, G., 1918 Uber die gluttenbildung von simpervivum. Flora 11 : 128-151.

Lang, A., 1952 Physiology of flowering. Ann. Rev. Plant Physiol. 3 :

Leopold, A. C., 1951 Photoperiodism in plants. Quar. Rev. Biol. 26: 247-263.

Lewis, C. F. and T. R. Rrchmond, 1957 The genetics of flowering response in cotton. I. Fruiting behavior of Gossypium hirsutum var. marie-galante in a cross with a variety of American Upland cotton. Genetics 42 : 499-509.

1960 The genetics of flowering response in cotton. II. Inheritance of flowering response in a Gossypium barbadense cross. Genetics 45 : 79-85.

Murneek, A. E., and R. O. Whyte, et al., 1948 Vernalization and Photoperiadism. Chronica Botanica Co. Waltham, Mass.

Wryte, R. O., 1946 Crop Production and Environment. Faber and Faber. London.

Wigglesworth, V. B., et al., 1948 Growth in Relation to Differentiation and Morphogenesis. Symposia Soc. Exptl. Biol. 2. Cambridge University Press. Cambridge. 